Mitteilungen der Österreichischen Geographischen Gesellschaft,

155. Jg. (Jahresband), Wien 2013, S. 45-60

\title{
REgIONAL INCOME INEQUALITIES AMONG EU NUTS 2 Regions, 1995 and 2010: Perspectives from a Geographically Weighted Approach ${ }^{1)}$
}

\author{
William H. Berentsen, and Robert G. CROMLEY, both Storrs, Connecticut, USA*
}

with 9 Figures in the text

\section{CONTENTS}

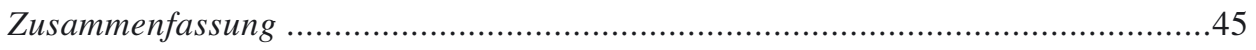

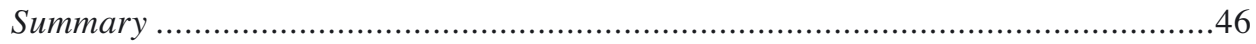

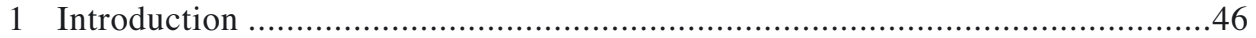

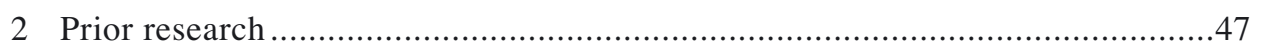

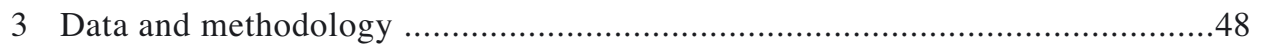

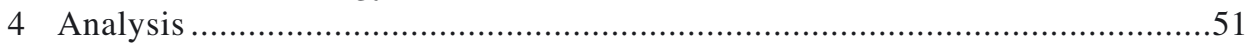

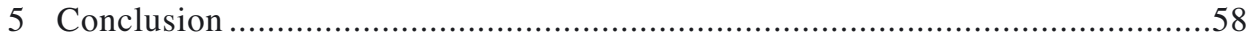

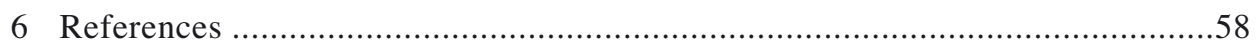

\section{Zusammenfassung}

Regionale Einkommensunterschiede zwischen NUTS-2-Regionen der EU, 1995 und 2010: Perspektiven aufgrund eines räumlich gewichteten Ansatzes

Der Beitrag bietet eine Untersuchung der Ungleichheiten zwischen Regionen der Ebene NUTS 2 der Europäischen Union gemessen am Bruttoinlandsprodukt pro Kopf der Bevölkerung, wobei der Index der Ungleichheit nach zwei unterschiedlichen Bandbreiten räumlich gewichtet wird. Jede der beiden Gewichtungen beruht auf Berechnungen von mehr als 260 Raumeinheiten sowohl für 1995 als auch für 2010. Danach gestaltete Karten der Ungleichheits-Indices bieten ein neuartiges Bild des relativen Niveaus räumlich gewichteter Ungleichheit aus der Perspektive jeder Region. Die Untersuchung verfolgt Änderungen der Muster von Ungleichheit zwischen

1) The authors gratefully acknowledge (a) the help of Marcello Graziano, Ph.D. student at the University of Connecticut, in acquiring 1995 regional GDP data for Italy, and (b) helpful comments on an earlier draft from the editor and two anonymous reviewers.

* William H. Berentsen, PhD., Professor, and Robert G. Cromley, PhD., both Department of Geography U-4148, University of Connecticut, 215 Glenbrook Rd., Storrs, CT 06269-4148; e-mail: william.berentsen @uconn.edu,http://geography.uconn.edu/people/faculty/william-berentsen; robert.cromley@uconn.edu, http://geography.uconn.edu/people/faculty/robert-cromley 
1995 und 2010 und bestätigt dabei die Ergebnisse früherer Studien. Die Ungleichheiten zwischen allen EU-Regionen sind offenbar im Schwinden begriffen, weil die Ungleichheiten zwischen dem östlichen und dem westlichen Europa abgenommen haben. Doch haben sie sich auf einem niedrigeren räumlichen Aggregationsniveau in etlichen Fällen verschärft.

\section{Summary}

The paper provides an investigation of inequalities in GDP per capita among European Union regions at the NUTS 2 level using a spatial weighting of the Index of Dissimilarity at two differing bandwidths, each based on calculations from one of over 260 regional centroids for both 1995 and 2010. Maps of inequality indices generated in this fashion provide a new view of relative levels of geographically weighted regional inequality from the perspective of each region. The study looks at changes in inequality patterns between 1995 and 2010, and reports results similar to previous studies. Inequalities among all EU regions appear to be declining as the result of decreasing inequalities between Eastern and Western Europe, though at the more local level, inequalities have increased in a number of cases.

\section{Introduction}

European Union (EU) regional inequalities are studied extensively owing to the Union's longstanding political commitments to reduce them (e.g., Treaty of Rome, 1957), as well as related to research funding opportunities and data collection efforts that encourage regional scientists who study the issue both among the EU's regions and across Europe more generally. This paper investigates regional income inequalities using geographically weighted indices of dissimilarity among most EU members' and candidate members' NUTS 2 regions, the latter based on consistent 2010 definitions. Use of a geographically (or "spatially") weighted index of dissimilarity allows emphasizing differences between a given EU region and those nearer to it, replicating within the results of estimated regional inequalities the heightened importance of relative location for all types of spatial interaction between regions, their institutions and inhabitants.

The research investigates and the paper reports on different levels of spatial weighting of inequality statistics based on selection of differing bandwidths focused on each of over 260 regional centroids, creating concentric rings of lessening weight for regions' per capita income levels within each successive ring with greater distance from an origin. Plots of inequality indices generated in this fashion for each of the more than 260 NUTS 2 regions provide a new view of relative levels of geographically weighted regional inequality from the perspective of each region. The study also looks at any changes in these patterns between 1995 and 2010, a period during which the Euro was introduced and became Europe's most important currency, as well as one of the 
world's most important. During the same period a large number of Central and East European countries also joined the Union or became candidate members, the latter further enhancing the importance of issues related to income inequality within and between Europe's countries and regions.

\section{Prior research}

While a great array of specific methods are being used to measure regional inequalities in Europe and elsewhere, two general types of research approaches are undertaken to investigate levels of inequalities, one, beta convergence, focused on both global outcomes (using analysis of temporal economic growth rates), and the other, sigma convergence, focused on measurements of both global and more region-specific outcomes, including temporally changing inequalities.

"Traditional empirical methodologies for testing convergence hypotheses are betaand sigma- convergence analysis. $\beta$-convergence is defined as a negative relation between the initial income level and the income growth rate. If poorer economies grow faster than richer ones, there should also be a negative correlation between the initial income level and the subsequent growth rate. Sigma-convergence ( $\sigma$-convergence) hypothesis examines the changes in variation of income between countries or regions. If this variation decreases over time the sigma-convergence hypothesis can be accepted." (PAas \& SchlitTe 2006, p. 8)

Most researchers studying the EU, notably regional economists, focus on investigating beta-convergence, seeking to establish an empirical, global pattern of change in economic growth rates and then model underlying causes. Researchers who, like us, investigate sigma-convergence focus on the patterns of regional dispersion of well-being, including especially income. A spatially homogeneous pattern of well-being, including income per capita, is a desired regional development outcome within the EU, which seeks "social" and "regional" cohesion, the latter meaning reduced regional inequalities. The sigma approach focuses more on outcomes for specific places, including regional groupings that have been long associated with lagging socio-economic development, such as parts of Eastern and Southern Europe like Italy's Mezzogiorno. Conditions in the latter regions concern both the EU and individual countries, with each spending much effort and expense in attempting to help support regional development, as well as regional and social equity.

Efforts to analyse both beta and sigma convergence have been undertaken for a very long time (e.g., [beta] B ARro \& S ALA-I-MArtin 1991, [sigma] Molle et al. 1980). Fingleton (2003), PaAs \& Schlitte (2006), Bosker (2008), Monfort (2008), Rapacki \& Próchniak (2009), Bouvet (2010), and LSE Enterprise et al. (2011) provide recent examples of investigations of income convergence within the EU. These researchers, and others using both beta and sigma approaches, indicate an apparently slow convergence trend in average regional incomes based on a varied, still-debated set of 
factors, notably ones dependent on a particular country, and also ones associated with development in dynamic metropolitan areas.

"The results show that the speed of convergence among regions in the EU is painfully slow. Furthermore, there is a distinct difference between convergence processes at the regional and at the national level. Especially in the EU-10 [the less prosperous East], the catching-up at the national scale seems to be driven by some growth centers, mainly capital regions. This causes tendencies to divergence at the regional scale. Tests for spatial autocorrelation reveal that regions are strongly affected in their development by neighbouring regions." (PAAs \& Schlitte 2006, p. 1).

Though results of investigations of beta convergence over the past two decades have not reached a consensus on either the existence or rate of "unconditional" growth convergence (ESPOSTI 2008), several recent studies using both beta and sigma approaches concur with a number of earlier ones in suggesting that declining levels of net, global inequality are evolving across the EU and are the result of decreases in between-country differences (e.g., [beta] SAla-i-Martin 1996, Meliciani 2006, Eckey \& Türck 2007, Esposti \& Bussoletti 2008; [sigma] PaAs \& Schlitte 2006, Bosker 2008, Beckfield 2009, Bouvet 2010, Bracalente \& Perugini 2010; [beta and sigma] Geppert \& Stephan 2008, Monfort 2008, Rapacki \& Próchniak 2009). Evidence suggests that the declines mute a counter-trend of frequent increases in within-country inequalities, especially the EU's poorer countries. On the other hand, there has been a long term trend of declining inequalities among regions in historically "old" or "Western" Europe.

This study will add two new dimensions to the large and evolving literature on European regional inequalities, one by adopting a geographically weighted evaluation of regional inequality levels and another by use of data up to 2010 .

\section{Data and methodology}

Data for the study derive from a recent update of 1995 and 2010 regional populations and regional GDPs (EUROSTAT 2013; converted when necessary to Euros and "standardized" for regional price levels by using PPS values (EUROSTAT 2012) for 265 NUTS 2 regions within all current EU members (including newly acceded Croatia), plus candidate member Macedonia. Eurostat provides good overviews of changes in NUTS 2 region boundaries (Eurostat 2002, 2003, 2007, 2011), though national information sources were also consulted to identify details. Outlying territories of countries beyond the immediate confines of Europe were not included, such as French Guyana, the Azores and Canary Islands, and Spanish holdings in North Africa. For similar reasons, it was also decided not to include Iceland. Data for Montenegro are not (yet) available for 1995, and it was not included. Eurostat (2013) provided nearly all data needed for 2010 , but about $20 \%$ of the total data points for the study came from national sources for 1995 , as described briefly below. 
Regional boundaries were those that existed in 2010, excepting in Croatia where 2009 boundaries for three regions were used instead of the two 2010 delimited regions (population and GDP values are still those from 2010). Within some countries there were problems obtaining 1995 values for 2010 defined regions, and in those cases (for two regions in Germany and the United Kingdom [UK], and for several regions in Finland), values for the regions were merged, divided equally, and reported as the same value for each area. In the case of Italy, estimates were used to adjust 1995 values for a quite small territory that switched between Marche and Emilia-Romagna, based on information from the NUTS 2 regions' web sites (Regione Emilia-Romagna 2012; Regione Marche 2012).

As noted above, for 2010 nearly all (about 98\%) entries came from EUROSTAT (2013). One regional NUTS 2 population data point for 2010 in Croatia was needed from another source, and it was used to help apportion GDP data (using three 2009 regional values and two 2010 regional values (one a merger of two 2009 defined regions), both from EurostaT). Other than the merged UK and Italian regional data and the 2009-2010 interpolated regional data point for Croatia (Republic of Croatia, 2011), all 2010 GDP data are as reported by Eurostat (2013).

Regional data collection for 1995 NUTS 2 values was a bigger challenge. For the 49 Austrian, Croatian, Hungarian and Italian NUTS 2 regions, data were acquired from the World Bank and national statistical institutes (World Bank 2013), Statistics Austria (2013), Republic of Croatia (2011), Hungarian Central Statistical Office (2009), ISTAT (2012), and, in the case of GDP, used along with a EuROSTAT data set to convert national currencies to Euros (EuROSTAT 2012). Interpolated regional GDP estimates were required and found for the Croatian regions (from 1991 and 2001 data). WorLD BANK data for GDP and GDP growth rates were used to estimate national income values for several single-region countries: Macedonia, Malta and Latvia, based in each case on values within one to four years of 1995 (WORLD BANK 2013). In the case of one region in Greece (Sterea Ellada) and three in the UK (Cumbria, Greater Manchester, and Lancashire) apparent errors (1995 values at the same levels as in 2010) within Eurostat data (2013) were replaced by data from Le Gallo \& ERTur (2000) and the UK's Office for National Statistics (2013), respectively.

Finally, note also that (1) reported GDP data for countries that have low tax collection efforts (allegedly, for example, Cyprus, Greece, Italy) are likely underestimated and (2) values for Croatia in 1995 are depressed (and possibly inaccurate) owing to the Balkan Wars at the time.

The Index of Dissimilarity, derived from use of the Lorenz Curve, was chosen as a measure of regional income inequality for this study. The Lorenz Curve is a common tool for measuring income inequality within a population (KAKWANI 1977). In a Lorenz Curve, the observations are rank ordered from low to high by the per capita income value of each observation. The cumulative frequency of income is plotted against the cumulative frequency of population, using this rank order with population given along the horizontal axis. If no income inequality exists, the Lorenz Curve follows a 45 degree straight line. If complete inequality exists, then the curve would follow the horizontal axis until the last observation and then follow a vertical line to the top. 
Two widely used numerical measures for measuring income inequality associated with the Lorenz Curve are the Gini Coefficient and the Index of Dissimilarity. The Gini Coefficient measures the area between the Lorenz Curve and the 45 degree line and the Index of Dissimilarity measures the maximum vertical distance between the Lorenz Curve and the 45 degree line. Both measures range in value from zero (no inequality) to one (full inequality).

Both measures are also "global" in nature - meaning that they are summary statistics for the entire study area. A current theme in geo-statistical analysis has been the development and use of local counterparts to global statistics (Fotheringham 1997). Different types of local statistics (see ANSELIN 1995; BRUNSDON et al. 2002; GETIS \& ORD 1992) have been developed to explore the non-stationarity of global parameters. Another aspect of these local statistics is that they can be mapped, and a visual interpretation of the results is an important component of the investigation (FoTHERINGHAM 1999).

Local analysis gives more influence to units within a spatial neighbourhood of a given location by geographically weighting each unit value. In the geographical weighting process, either a spatially fixed or a spatially adaptive filter is commonly used to determine the nature of the spatial neighbourhoods (Fotheringham et al. 2002). A spatially fixed filter uses a constant bandwidth distance around a location to determine the spatial extent of the influence of units for each neighbourhood. In contrast, a spatially adaptive filter allows the bandwidth distance to fluctuate from location to location in order to ensure at least a certain number of units lie within the bandwidth distance of each neighbourhood. Kernel functions (e.g., a Gaussian function or a bi-square function) are used in conjunction with either type of filter to establish the rate of distance decay for each geographic weight. The bandwidth parameter associated with the kernel function determines the geographic scale for the analysis. As the bandwidth becomes very large, a small scale analysis is performed in which the estimated statistics are fairly constant with respect to location (the global perspective) but, as the bandwidth becomes small, a large scale analysis is performed in which the estimated statistics vary widely with respect to location (the local perspective).

This research uses a local version of the Index of Dissimilarity to determine how income equality varies across the European Union. The global Index of Dissimilarity (GID) is defined as:

$$
\begin{gathered}
n \\
G I D=0.5 \sum / I_{i}-P_{i} / \\
i=1
\end{gathered}
$$

where, $I_{i}$ is the proportion of total income associated with the $i^{\text {th }}$ NUTS unit and $P_{i}$ is the proportion of total population associated with the same unit. The local Index of Dissimilarity (LID $)$ was developed by LLOYD et al. (2004) to measure segregation levels in Northern Ireland and is adapted here to measure local income inequality. For this analysis, a spatially fixed filter with a Gaussian kernel function is used to measure income inequality for a given bandwidth distance: 
$n$

$$
\begin{aligned}
& \qquad I D_{j}(b)=0.5 \sum /\left(w_{i j} I_{i} / \sum w_{i j} I_{i}\right)-\left(w_{i j} P_{i} / \sum w_{i j} P_{i}\right) / ; \\
& \text { where, } \\
& \qquad \begin{array}{c}
n=1 \\
w_{i j}=\exp \left(-0.5 d_{i j}^{2} / b^{2}\right) / \sum \exp \left(-0.5 d_{i j}^{2} / b^{2}\right) . \\
i=1
\end{array}
\end{aligned}
$$

In equation (3), $d_{i j}$ is the distance between the $i^{\text {th }}$ and $j^{\text {th }}$ places, and $b$ is a bandwidth distance. By changing the bandwidth distance, more local (or "regional") versus more interregional trends in income inequality can be examined.

\section{Analysis}

Figure 1 displays the geographic distribution of per capita income in 1995 and 2010. In each map in this paper, an equal interval classification is used in order to portray the magnitude of differences in per capita income more accurately. In 1995, there were only four NUTS 2 regions (Luxembourg and three urban units) that had per capita incomes in the highest category, and also a small number of West European regions in the second highest category. Most European regions were in the lower two income intervals, with most of Northern and Northwestern Europe in the higher of those. Most of Eastern Europe and much of Southern Europe were in the lowest category. There is a quite clear, North-South income boundary through Central Europe that followed the "Iron Curtain" or "Cold War" political boundaries between the "freer", more prosperous West and the less prosperous East. The boundary in Central Europe is well illustrated by the higher Austrian regional incomes (except in the case of Burgenland) in comparison to all regions among its eastern neighbours, excepting the small Slovak capital region around Bratislava.

In 2010 , there were only two European regions in the highest income category (Luxembourg and Central London) and also very few in the second highest category. Overall, the number of units in the lowest category increased between 1995 and 2010, and included not only Eastern and Southern Europe but also much of France and the United Kingdom. At a local or "regional" level though, several national capital units in Eastern Europe moved into the second category along with many of the moderately prosperous regions in Central and Western Europe. Comparing the two maps, the relative improvement of parts of Eastern Europe in relation to many areas in Western Europe is fairly clear.

The reason behind these changes was the differential rates of income growth in different parts of the European Union. Figure 2 displays the pattern of the percent change in per capita income between 1995 and 2010. A natural breaks classification is used to produce the most homogeneous grouping of countries. Within the European Union, the highest growth rates were in Eastern Europe and within Eastern Europe the capital regions had the highest rates. Much of Central and Western Europe, on the other hand, experienced relatively slow growth. 


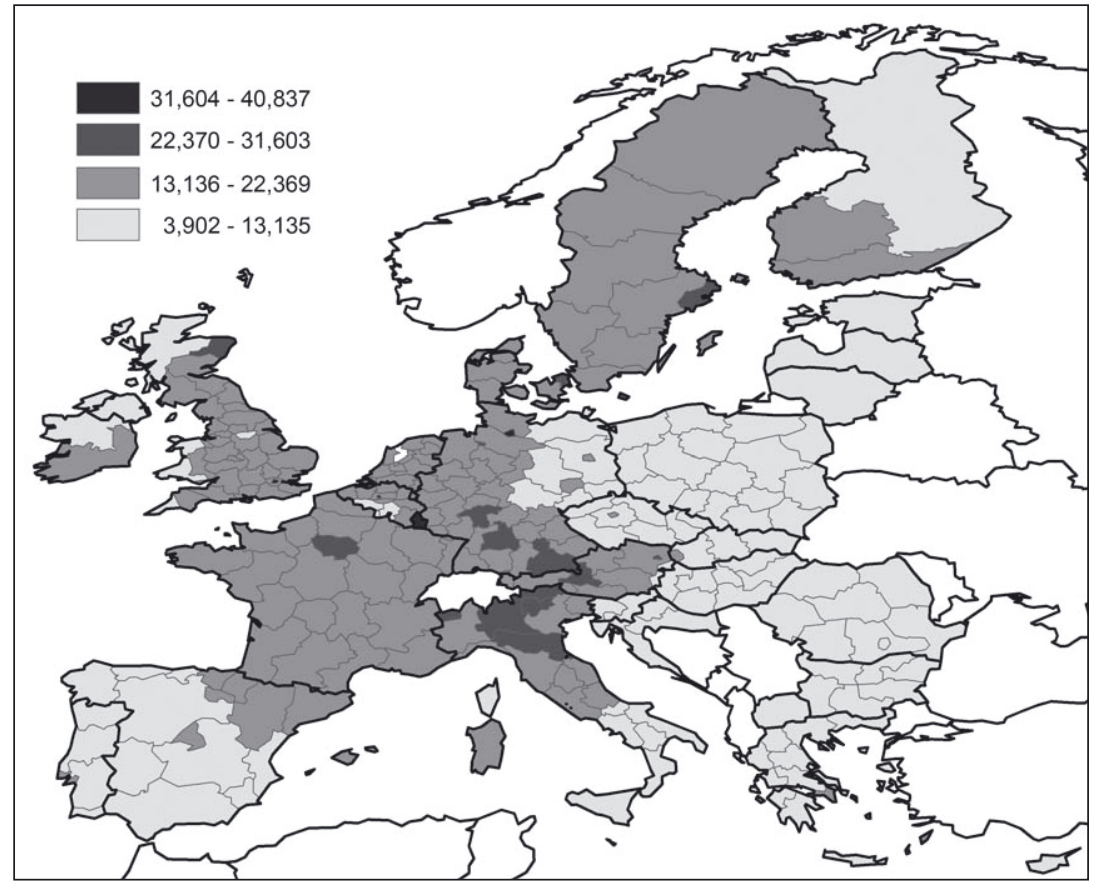

Fig. 1a: GDP per capita in Euros (PPS), 1995²)

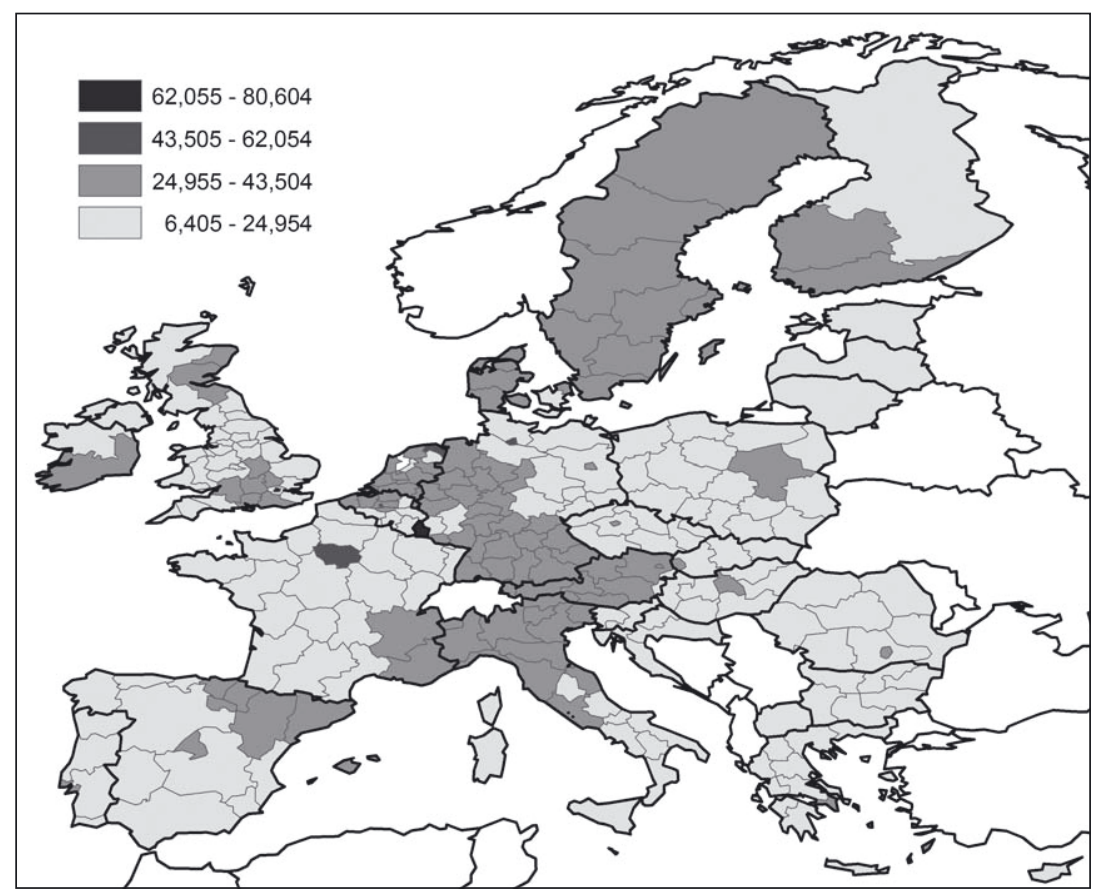

Fig. 1b: GDP per capita in Euros (PPS), 2010 


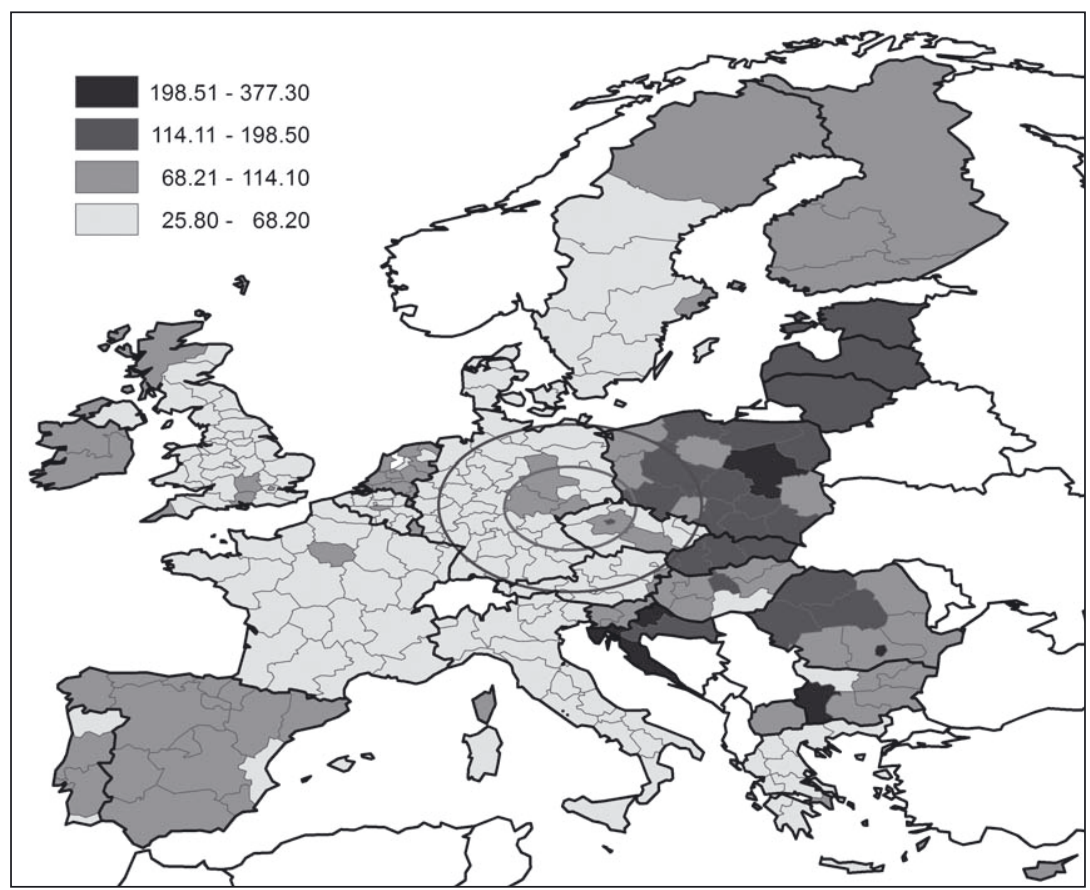

Fig. 2: Percent change in GDP per capita (PPS) between 1995 and 2010

These changes in per capita income are reflected in the changes in income inequality between 1995 and 2010 (Figures 3 and 4). To examine income inequality at a local, or regional, level, a $200 \mathrm{~km}$ bandwidth is chosen. The inner ring in Figure 2 corresponds to a $200 \mathrm{~km}$ radius around the NUTS 2 unit of Chemnitz (Germany). For a more interregional depiction of income inequality, a $400 \mathrm{~km}$ bandwidth is chosen (the outer ring in Figure 2 corresponds to a $400 \mathrm{~km}$ radius around Chemnitz). Overall, the global Index of Dissimilarity decreased from 0.17010 in 1995 to 0.14163 in 2010 . This is the result of the much higher growth rates in per capita during the time period by regions that had lower incomes in 1995, such as in most of Eastern Europe.

However, the changes in the pattern of local income inequality are more nuanced. Figure 3a displays the local or regional Index of Dissimilarity for 1995 at the $200 \mathrm{~km}$ bandwidth. A diverging color scheme is used in which the global value of 0.17010 is used as the break between the pale grey hues and the dark hues. A fixed interval length of one-half the global value ( 0.08505 in this case) is used to further subdivide the range of values into four classes. The areas with higher income inequality than the global value are located in the Central European regions (including eastern Austria) separating Western from Eastern Europe. The highest local or regional inequality is in Estonia, which is between the poorer country of Latvia and the much wealthier

2) Not representing Kosvoa/Kosovo in this and the following figures does noct mean any political statement. 


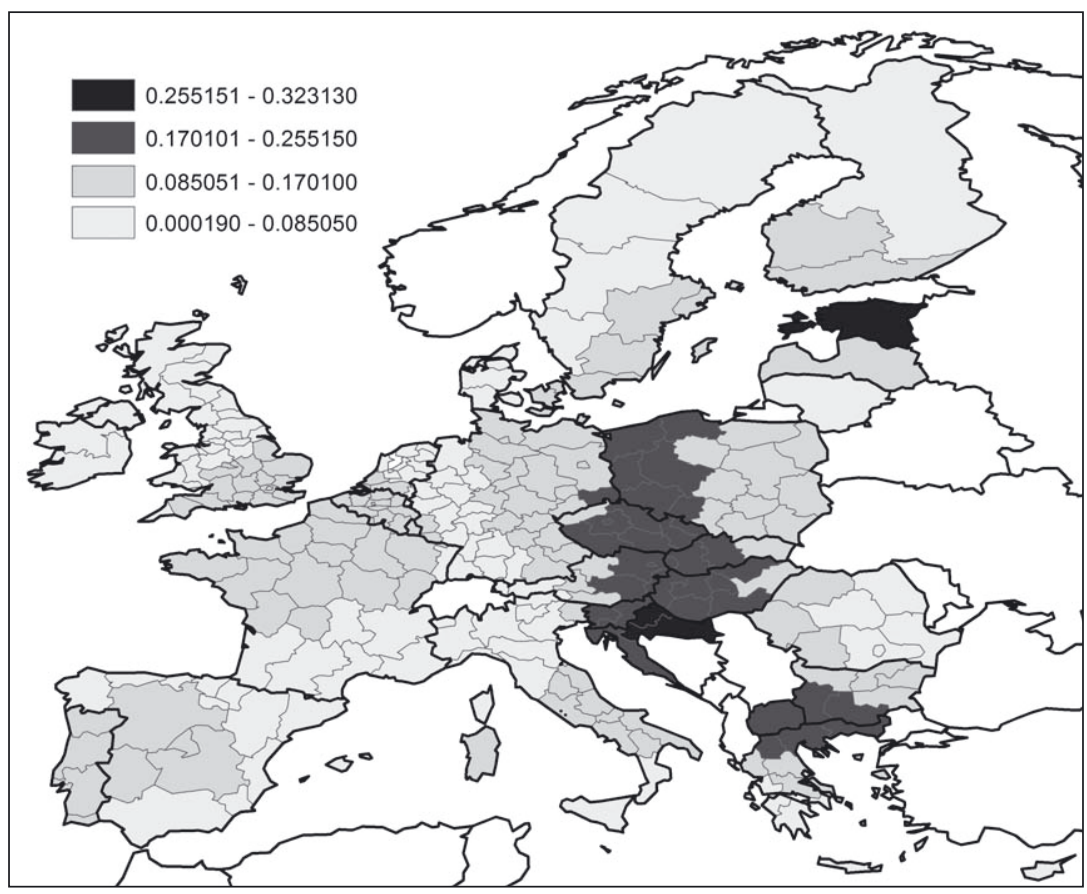

Fig. 3a: Local (regional) Index of Dissimilarity for 1995 at the $200 \mathrm{~km}$ bandwidth

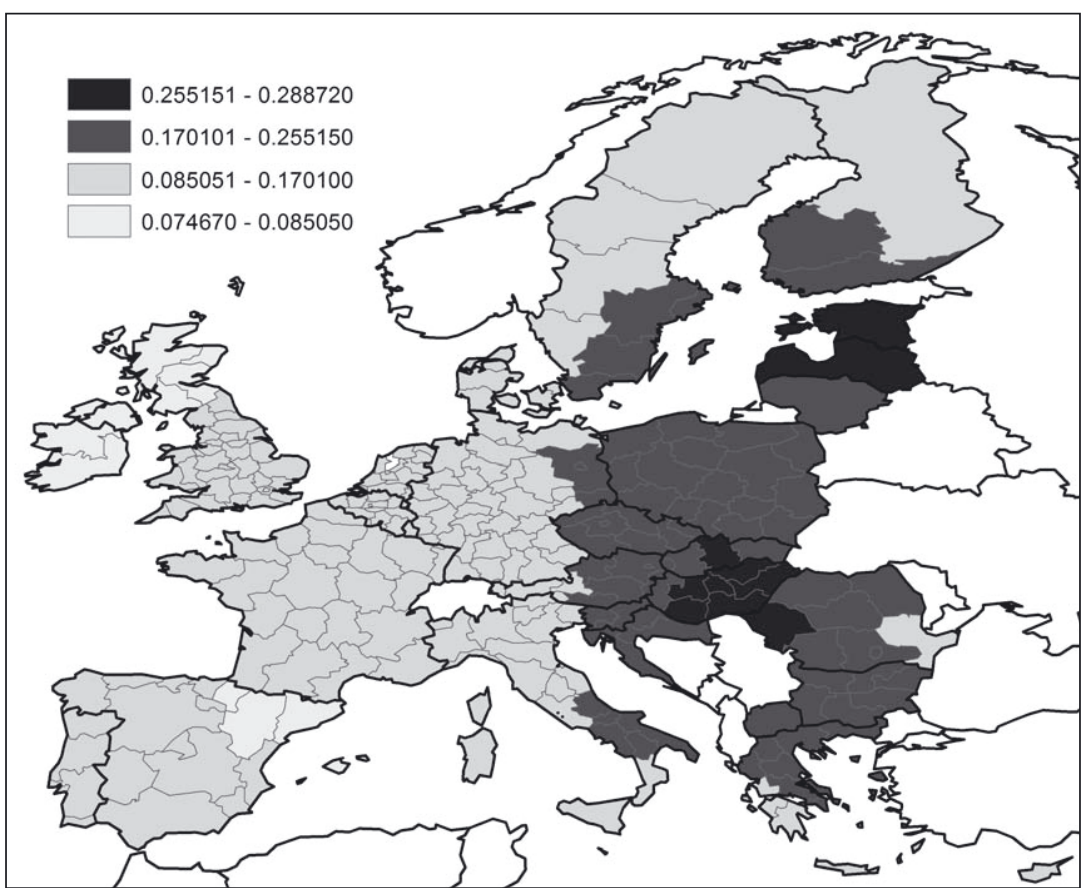

Fig. 3b: Interregional Index of Dissimilarity for 1995 at the $400 \mathrm{~km}$ bandwidth 


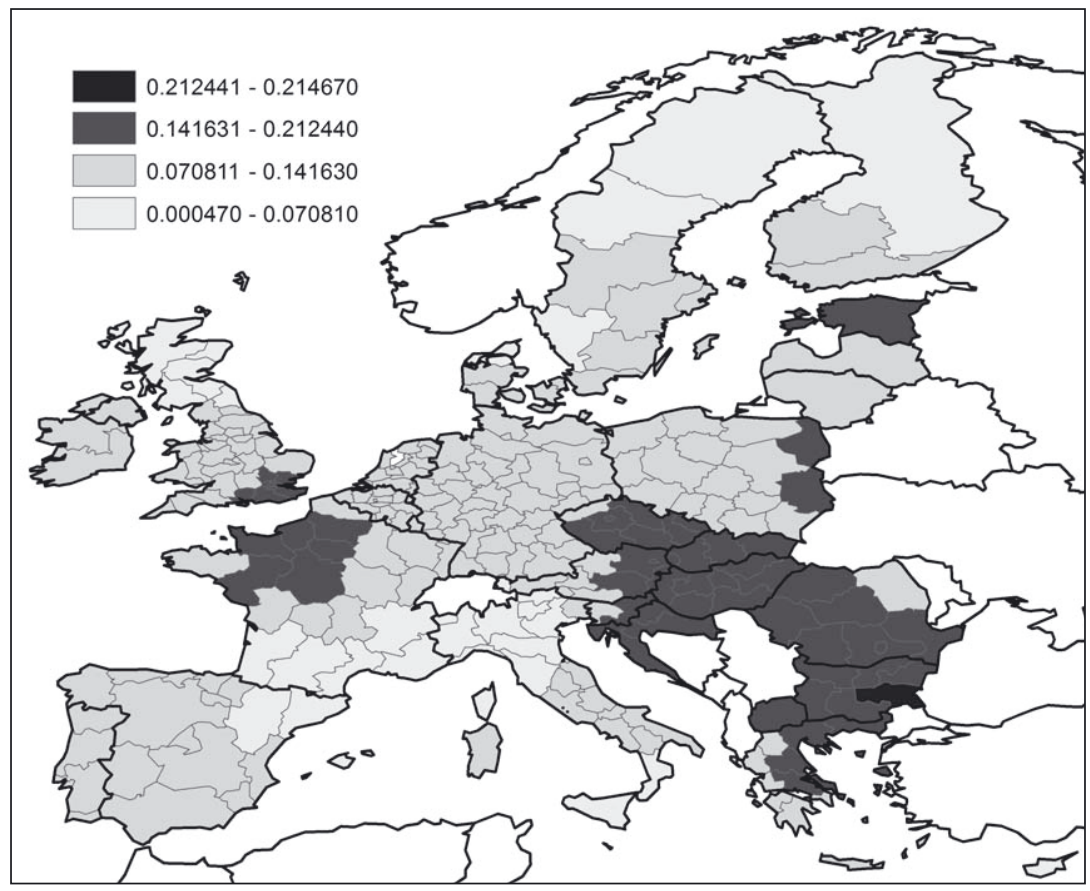

Fig. 4a: Local (regional) Index of Dissimilarity for 2010 at the $200 \mathrm{~km}$ bandwidth

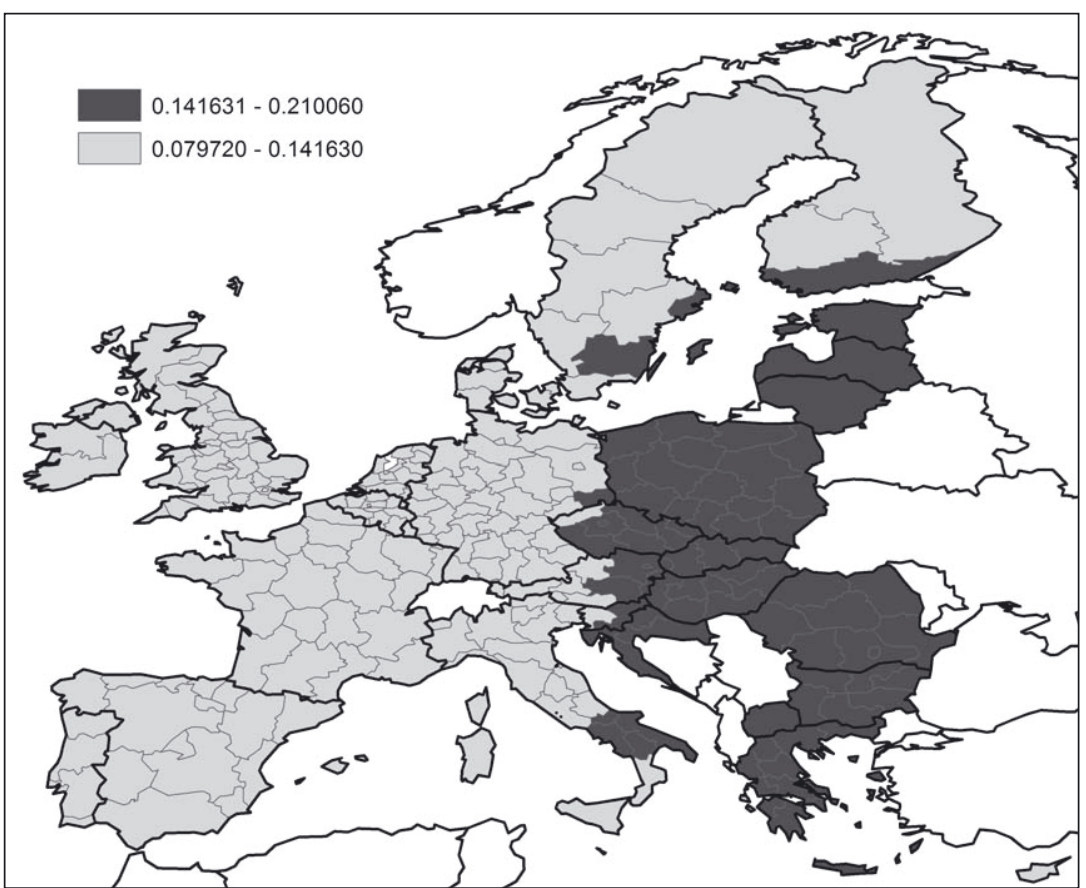

Fig. 4b: Interregional Index of Dissimilarity for 2010 at the $400 \mathrm{~km}$ bandwidth 
units of southern Finland. The lowest levels of inequality occur either in regions like western Germany, where many neighbouring regions have similarly, relatively high income levels and, for example, in Lithuania and eastern Romania where the opposite situation existed.

Figure 3b displays the interregional Index of Dissimilarity for 1995 using the 400 $\mathrm{km}$ bandwidth, with the same classification logic as in Figure 3a. At this interregional scale, the main pattern was the West to East distinction between lower level of inequality in the more uniformly prosperous Western Europe and higher levels of income inequality in East European regions that had prosperous Western and relatively poor East European neighbours.

In 2010, these patterns change somewhat, at least in part because of the declining level of European-wide inequalities, largely related to improved conditions in Eastern Europe. Figure 4 displays the Index of Dissimilarity for 2010 using the 200 $\mathrm{km}$ (Fig. 4a) and the $400 \mathrm{~km}$ (Fig. 4b) bandwidths and the same classification logic as in Figure 3. At the more local or regional level, areas around London and Paris in the West had higher income inequality than the global level, whereas much of Poland now had lower than the global level of income inequality (see Fig. 4a). The per capita incomes in the areas around London and Paris are higher than those in Poland, but the western areas fell behind the greater growth in income in London and Paris. The highest level of local inequality was now in Bulgaria due to the greater increase in income in the Sofia [Sofija] capital region than those areas surrounding it.

At the interregional level, the same West to East dichotomy in inequality continued to exist (see Fig. 4b), owing both to inequalities within Eastern Europe and between the East and West. Note that inequality levels decline far enough between 1995 and 2010 that two (rather than four) inequality index categories encompass differences between European NUTS 2 regions when employing the $400 \mathrm{~km}$ bandwidth in 2010 (see Fig. 4b).

Although the global index of inequality declined between 1995 and 2010, the local and interregional levels of inequality did not decline unilaterally among the different NUTS 2 units. Figure 5 displays the differences in inequality levels over the time period. The value for 1995 is subtracted from the value for 2010 so that negative values denote an increase in income inequality over the time period and positive values denote a decline over time. At the more local level, the decreases in inequality occurred mainly in Central Europe and the western part of Eastern Europe (see Fig. 5a), most notably in relatively economically successful regions including Estonia, western Poland, Slovenia and western Croatia.

At the interregional level, most of the European Union (most notably Central and many parts of Eastern Europe) experienced a decline in the index values, although regions in West and Northwestern Europe (Ireland, the UK, the Low Countries, northwestern Germany, France, and northern Spain), as well as eastern Romania and Bulgaria experienced increased inequality (see Fig. 5b). 


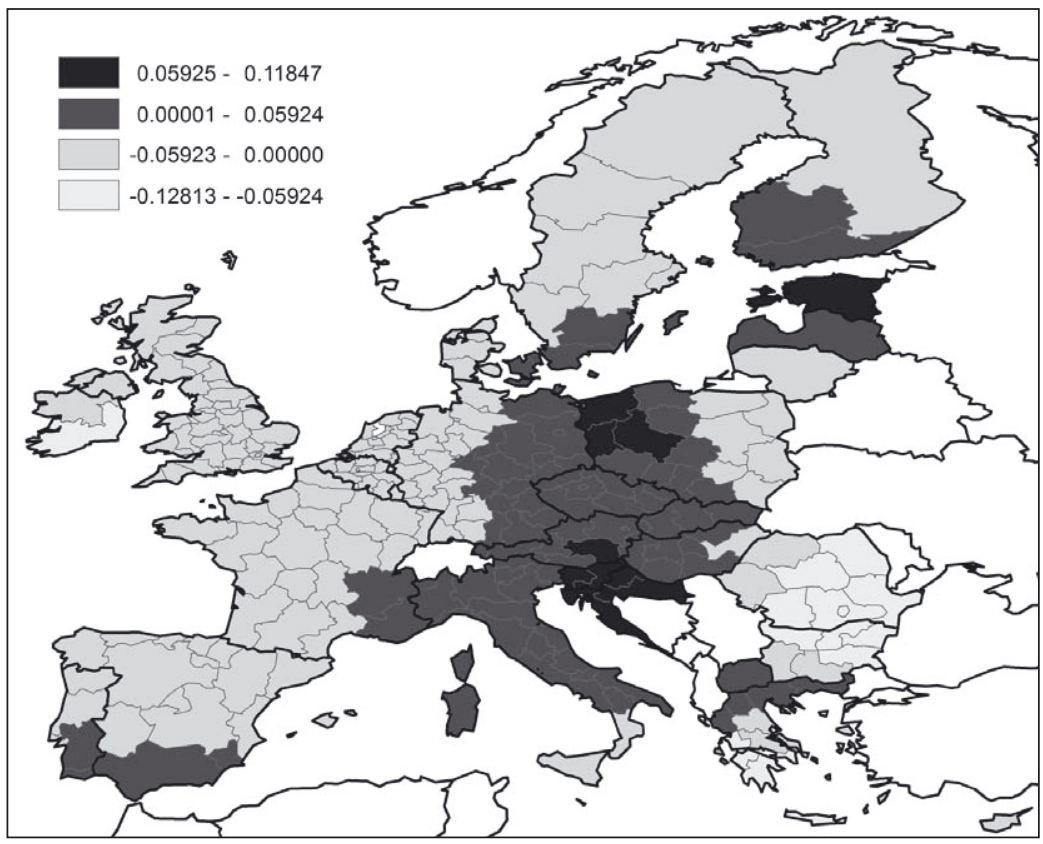

Fig. 5a: Difference in local (regional) Index of Dissimilarity (200 km BW): 2010 value minus 1995 value

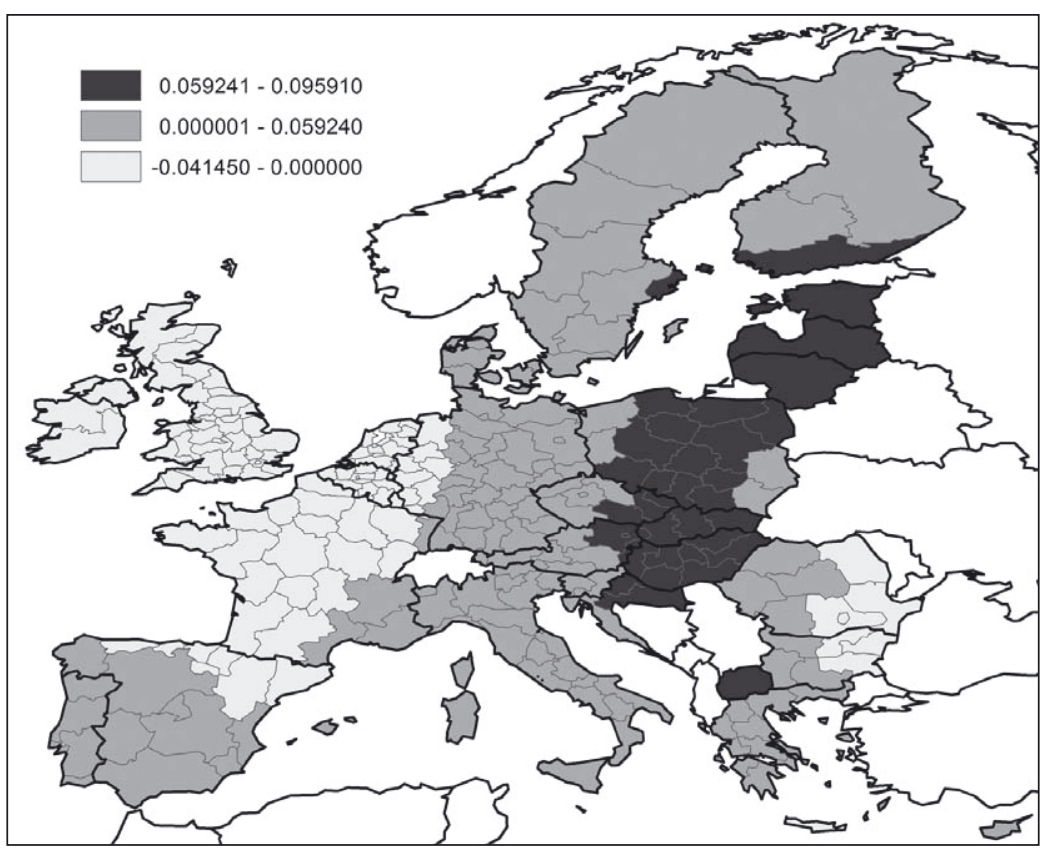

Fig. 5b:Difference in interregional Index of Dissimilarity (400 km BW): 2010 value minus 1995 value 


\section{Conclusion}

The results of this paper report geographically weighted inequalities for Europe's NUTS 2 regions in both 1995 and 2010. Consistent with most of the existing literature covering earlier time periods for Europe and the EU, our results indicate that inequalities have declined between Eastern and Western Europe (i.e., the global level of inequalities has declined), though a still notable divide remains, as indicated by the North-South "ridges" of highest inequality in Central Europe between East and West for 2010 (see Fig. 4a and 4b).

The approach used here also provides relatively rich detail at the local and interregional levels, indicating, for example, increased inequalities within some areas in both Western and Eastern Europe (see Fig. 5a and 5b) - a confirmation of a trend found in other studies of increased within country inequalities and declining inequalities between countries, in particular across the former East-West "Cold War" boundary. The approach used here enhances the view of these geographical variations owing to the amplified weighting of nearby in comparison to far-off locations.

In association with providing a new, geographically weighted, methodological approach to assessing inequalities within regions, this study also presents a perspective that purposely assesses a region's inequality based more heavily on nearby regions, taking into account an inherent, geographically based "relative wealth or poverty" perspective. That is, some people will, at least in part, base their perceptions of relative wealth or poverty on comparisons with near neighbours. Thus, people within regions of the UK and France may feel as "poor" in comparison to the Paris and London regions as they do "wealthy" in comparison to the far off Balkans. Conversely, people in the Prague [Praha], Warsaw [Warszawa], and Budapest regions live within a geographical "peak" of income and astride a "ridge" of relative well-being in comparison to the still-lagging, more rural regions of Eastern Europe. Of course, this effect could be enhanced (or diminished) by varying the "field of vision" - or bandwidths, as illustrated by way of our examples - in future applications of the approach used in this paper. In addition, future research might provide further insights into patterns of inequality by way of using alternative measures of geographically diverse levels of well-being measured by, for example, variables related to the employment, educational attainment or health status of subregions within the EU or other geographically defined regions.

\section{References}

AnSELIN L. (1995), Local indicators of spatial association-LISA. In: Geographical Analysis, 27, pp. 93-115.

Barro R., Sala-I-Martin X. (1991), Convergence across States and Regions. In: Brookings Papers on Economic Activity (BPEA), Brookings Institution, 1, pp. 107-158.

BeCKFIELd J. (2009), Remapping Inequality in Europe: The Net Effect of Regional Integration on Total Income Inequality in the European Union. In: International Journal of Comparative Sociology, 50, 5-6, pp. 486-509. 
Bosker M. (2008), The spatial evolution of regional GDP disparities in the "old" and "new" Europe. In: Papers in Regional Science, 88, 10, pp. 3-27.

Bouvet F. (2010), EMU and the dynamics of regional per capita income inequality in Europe. In: Journal of Economic Inequality, 8, 3, pp. 323-344.

Bracalente B., Perugini C. (2010), The components of regional disparities in Europe. In: Annals of Regional Science, 44, pp. 621-645.

Brunsdon C., Fotheringham A., Charlton M. (2002), Geographically weighted summary statistics - a framework for localised exploratory data analysis. In: Computers, Environment and Urban Systems, 26, 6, pp. 501-524.

ECKEy H.F., TÜrCK M. (2007), Convergence of EU Regions: A Literature Report. In: Investigaciones Regionales, 10, pp. 5-32.

Esposti R. (2008), Regional Convergence and EU Policies: Empirical Evidence and Measuring Problems. In: CESifo Forum, 9, 1, pp. 14-22.

Esposti R., Bussoletti S. (2008), Impact of Objective 1 Funds on Regional Growth Convergence in the European Union: A Panel-data Approach. In: Regional Studies, 42, 2, pp. 159-173.

Eurostat (2002), European Regional Statistics Changes in the NUTS classification 1981-1999. Luxembourg, European Communities.

Eurostat (2003), Regions Nomenclature of territorial units for statistics NUTS 2003/EU-15, Parts 1 and 2. Luxembourg, European Communities.

Eurostat (2007), Regions in the European Union: Nomenclature of territorial units for statistics NUTS 2006 /EU-27. Luxembourg, European Communities.

Eurostat (2011), Regions in the European Union Nomenclature of territorial units for statistics NUTS 2010/EU-27. Luxembourg, European Communities.

Eurostat (2012), Purchasing power parities (PPPs), price level indices and real expenditures for ESA95 aggregates. - http://appsso.eurostat.ec.europa.eu/nui/show.do? dataset $=$ prc_ ppp_ind\&lang =en (Last accessed October 16, 2012)

Eurostat (2013), Gross domestic product (GDP) at current market prices by NUTS 2 regions. - http://appsso.eurostat.ec.europa.eu/nui/show.do? dataset $=n a m a \_r \_e 2 g d p \& l a n g=e n$ (Updated through March 21, 2013; last accessed March 27, 2013)

FingLEton B. (2003), Models and Simulations of GDP per Inhabitant across Europe's Regions: A Preliminary View. In: Fingleton B. (ed.), European Regional Growth: Advances in Spatial Science, pp. 11-53. Berlin - Heidelberg, Springer.

Fotheringham A. (1997), Trends in quantitative methods I: Stressing the local. In: Progress in Human Geography, 21, pp. 88-96.

Fotheringham A. (1999), Trends in quantitative methods III: Stressing the visual. In: Progress in Human Geography, 21, pp. 88-96.

Fotheringham A., Brunsdon C., Charlton M. (2002), Geographically Weighted Regression: The Analysis of Spatially Varying Relationships. Chichester (UK), Wiley.

Geppert K., Stephan A. (2008), Regional disparities in the European Union: Convergence and agglomeration. In: Papers in Regional Science, 87, 2, pp. 193-217.

Getis A., ORD J. (1992), The analysis of spatial association by use of distance statistics. In: Geographical Analysis, 24, pp. 189-206.

Hungarian Central Statistical Office (2009), National Accounts Hungary 1995-2007. Budapest. - http://www.ksh.hu/docs/hun/xftp/idoszaki/monsz/monsz9507.pdf

Istituto Nazionale di Statistica (ISTAT) (2012), Unpublished regional regional GDP data. Rome.

KAKWANI N.C. (1977), Applications of Lorenz curves in economic analysis. In: Econometrica, 45,3 , pp. 719-728.

Le Gallo J., ERTUR C. (2000), Exploratory Spatial Data Analysis of the distribution of regional per capita GDP in Europe, 1980-1995. Unpublished paper, University of Burgundy. - http:// 
scholar.google.com/scholar_url?hl=en\&q=http://citeseerx.ist.psu.edu/viewdoc/downlo ad\%3Fdoi\%3D10.1.1.197.2887\%26rep\%3Drep1\%26type\%3Dpdf\&sa=X\&scisig $=A A G$ Bfm1n6zH9nHcJ9JoWgbgTAbWhh7Wx1A\&oi=scholarr (Last accessed, May 25, 2013)

Lloyd C., Shuttleworth I., McNair D. (2004), Measuring local segregation in Northern Ireland. International Population Geography Conference, University of St. Andrews. - http:// www.qub.ac.uk/c-star/selectedoutputs.htm (Last accessed, May 25, 2013)

LSE Enterprise, Vienna University of Economics and Business, University of Helsinki and Centre for Social and Economic Research (CASE) (2011), Study on the Impact of the Single Market on Cohesion: Implications for Cohesion Policy, Growth and Competitiveness (report to the European Commission). - http://ec.europa.eu/regional_policy/ sources/docgener/studies/pdf/single_market/single_market_report.pdf

Meliciani V. (2006), Income and Employment Disparities across European Regions: The Role of National and Spatial Factors. In: Regional Studies, 40, 1, pp. 75-91.

Molle W., van Holst B., Smith H. (1980), Regional Disparity and Economic Development in the European Community. Farnborough (UK), Saxon House, Teakfield Ltd.

Monfort P. (2008), Convergence of EU regions: Measures and evolution. European Union Regional Policy Working Papers no. 1. - http://ec.europa.eu/regional_policy/sources/ docgener/work/200801_convergence.pdf

Office for National Statistics (UK) (2013), Interim Mid-2011 Population Estimates for Primary Care Organisations in England by Single Year of Age and Sex; based on the results of the 2011 Census (September 25,2011). - http://www.ons.gov.uk/ons/interactive/censusmap-2-1---pop-density/index.html (Last accessed November 18, 2012)

PaAs T., Schlitte F. (2006), Regional Income Inequality and Convergence Processes in the EU25. ERSA conference papers, European Regional Science Association. - http://ideas. repec.org/p/wiw/wiwrsa/ersa06p229.html (ersa06p229) (Last accessed, May 25, 2013)

RAPACKi R., Próchniak M. (2009), Real beta and sigma convergence in 27 transition countries, 1990-2005. In: Post-Communist Economies, 21, 3, pp. 307-326.

Regione Emilia-Romagna (2012), Population data from E-R Statistica. - http://sasweb.regione. emilia-romagna.it/statistica/SceltaParametri.do (Last accessed March 4, 2013).

Regione Marche (2012), Population data from Sistema Informativo Statistico. - http://statistica. regione.marche.it/Home/Datieprodotti/Argomenti/Popolazione/Tavolestatistiche/tabid/121/ Default.aspx (Last accessed March 4, 2013).

Republic of Croatia, Croatian Bureau of Statistics (2011), 2011 Statistical Yearbook of Croatia. Zagreb.

S ALA-I-Martin X. (1996), The Classical Approach to Convergence Analysis. In: The Economic Journal, 106, 437, pp. 1019-1036.

Statistics Austria (2013), GDP and population data. - http://www.statistik.at/web_en (Last accessed on October 14, 2012)

Treaty of Rome, 1957 (Treaty Establishing the European Economic Community [EEC Treaty or Treaty of Rome]) 298 U.N.T.S. 11.

WoRLD BANK (2013), World DataBank. - http://databank.worldbank.org/data/home.aspx (Last accessed May 25) 